\title{
Mechanical properties and deformation behaviour of Fe-(20/27)Mn-4Al-0.3C austenitic steels
}

\author{
Biao Ma, Changsheng $\mathrm{Li}^{\mathrm{a}}$, Yahui Han, Yanlei Song, and Liqing Chen \\ State Key Laboratory of Rolling and Automation, Northeastern University, Shenyang 110819, \\ PR China
}

\begin{abstract}
The mechanical properties of the Fe-20Mn-4Al-0.3C (20Mn) and Fe-27Mn4Al-0.3C (27Mn) austenitic steels are investigated, and the deformation behavior under uniaxial tension was analysed. The $20 \mathrm{Mn}$ steel displays superior tensile properties to steel $27 \mathrm{Mn}$, but the latter has a higher work hardening rate at the onset of deformation. The medium stacking fault energy (SFE) of the two steels impedes the boom of deformation twinning and promotes the appearance of microbands in the late stage of straining, so that the work hardening rate is monotonously diminishing and fails to rise again. The maximum volume fraction of twin lamellae is less than $8 \mathrm{vol} \%$, and their mean spacing was also estimated. The distribution of grain orientation spread (GOS) indicates that twinning process contributes to relieving the locally high distortion generated by the dislocation cross-slip inside the grains, which improves the uniform plasticity. The $27 \mathrm{Mn}$ steel keeps a much higher toughness than $20 \mathrm{Mn}$ steel for each temperature. The Charpy impact energy of steel $27 \mathrm{Mn}$ after annealing reaches $310 \mathrm{~J}$ and $188 \mathrm{~J}$ at room temperature and $-196^{\circ} \mathrm{C}$, respectively.
\end{abstract}

\section{Introduction}

The Fe-Mn-Al-C austenitic steels are one of the highly attractive structural materials for the wide application in the manufacture of non-magnetic or cryogenic parts, as well as in the automotive industry [1-3]. More attention has been focused on the two representative chemical composition groups of $\mathrm{Fe}-(18-22) \mathrm{Mn}-0.6 \mathrm{C}-(0-2) \mathrm{Al}$ [4-6] and Fe-(26-28)Mn-(9-12)Al-(0.6-1.2)C steels [7, 8]. The former usually has the yield strength around $300 \mathrm{MPa}$ and tensile strength above $800 \mathrm{MPa}$ because of their outstanding twinning induced plasticity (TWIP) effect, whereas the superior strength and plasticity in the latter originate from the high $\mathrm{C}$ and $\mathrm{Al}$ content, nano-sized (Fe, $\mathrm{Mn})_{3} \mathrm{AlC}_{x}$ ( $\kappa$-carbide) and microbands induced during plastic deformation (MBIP). However, there are limited investigations on the Fe-Mn-Al-C austenitic steels with the combination of high Mn, medium $\mathrm{C}$ and $\mathrm{Al}$ additions. Most of these steels have the medium stacking fault energy (SFE) of 40-60 mJ/m². They usually keep better resistance to both martensite transformation and carbide precipitation, resulting in the maintenance of non-magnetism for the structural parts strengthened by cold working. Furthermore, the medium SFE

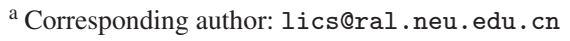

This is an Open Access article distributed under the terms of the Creative Commons Attribution License 4.0, which permits unrestricted use, distribution, and reproduction in any medium, provided the original work is properly cited. 
Table 1. Chemical composition of the experimental steels (in wt.\%).

\begin{tabular}{|l|c|c|c|c|c|c|c|c|c|}
\hline Steel & $\mathrm{C}$ & $\mathrm{Mn}$ & $\mathrm{Al}$ & $\mathrm{Si}$ & $\mathrm{V}$ & $\mathrm{P}$ & $\mathrm{S}$ & $\mathrm{N}$ & $\mathrm{Fe}$ \\
\hline $20 \mathrm{Mn}$ & 0.298 & 20.56 & 4.11 & 0.45 & 0.11 & 0.006 & 0.002 & 0.015 & bal. \\
\hline $27 \mathrm{Mn}$ & 0.297 & 27.01 & 4.21 & 0.28 & 0.09 & 0.003 & 0.006 & 0.006 & bal. \\
\hline
\end{tabular}

Table 2. Tensile properties and SFE of the experimental steels.

\begin{tabular}{|l|c|c|c|c|}
\hline Steel & Yield strength (MPa) & Tensile strength (MPa) & Elongation (\%) & SFE $\left(\mathrm{mJ} / \mathrm{m}^{2}\right)$ \\
\hline $20 \mathrm{Mn}$ & 306 & 603 & 48 & 41 \\
\hline $27 \mathrm{Mn}$ & 275 & 587 & 46 & 52 \\
\hline
\end{tabular}

ensures these steels to possess good mechanical properties particularly at the cryogenic temperature for the reason that the reduced SFE by descending temperature is more favourable for twinning process. This paper aimed at investigating the mechanical properties of $\mathrm{Fe}-(20 / 27) \mathrm{Mn}-4 \mathrm{Al}-0.3 \mathrm{C}$ austenitic steels with the medium SFE, and correlating their strain hardening behaviour to the analysis on the microstructure evolution during deformation by means of interrupted tensile test, electron backscattered diffraction (EBSD) and transmission electron microscopy (TEM).

\section{Experimental}

The chemical composition (wt.\%) of the Fe-20Mn-4Al-0.3C (20Mn) and Fe-27Mn-4Al-0.3C (27Mn) austenitic steels is listed in Table 1 . The steel billets were homogenized at $1200^{\circ} \mathrm{C}$ for $2 \mathrm{~h}$, hot rolled to the final thickness of 4 and $11 \mathrm{~mm}$, respectively, in the temperature range of $1100-900{ }^{\circ} \mathrm{C}$, and both followed by the annealing at $930^{\circ} \mathrm{C}$ for $30 \mathrm{~min}$.

The tensile samples with a gauge length of $50 \mathrm{~mm}$ were cut from the $4 \mathrm{~mm}$ thick annealed plate along the rolling direction. The tensile tests at room temperature were carried out using CMT5105 universal tensile testing machine at the constant strain rate of $10^{-3} \mathrm{~s}^{-1}$. The interrupted tensile tests for both steels were performed at different true strains $(\varepsilon=0.15,0.22,0.29$ and 0.36$)$ in order to examine the deformed microstructure by EBSD and TEM. The area fraction of deformation twins was estimated from the metallographs with the aid of an image analysis software. The EBSD data were obtained using a Zesis ULTRA 55 field emission scanning electron microscope (SEM), and analyzed by TSL OIM software. The step size was $0.5 \mu \mathrm{m}$. TEM examination for deformed microstructure was conducted by a FEI Tecnai G2F20 microscope operated at $200 \mathrm{kV}$. The Vickers hardness was evaluated on a KB3000BVRZ macro-hardness tester. The Charpy impact tests in the temperature range from $-196{ }^{\circ} \mathrm{C}$ to $30^{\circ} \mathrm{C}$ were performed on an Instron $9250 \mathrm{HV}$ instrumented impact testing machine. The V-notch specimens with a dimension of $55 \mathrm{~mm} \times 10 \mathrm{~mm} \times 10 \mathrm{~mm}$ were machined from the $11 \mathrm{~mm}$ thick annealed plate along the rolling direction.

\section{Results and discussion}

\subsection{Tensile deformation behaviour}

The hot rolled plates were annealed at $930^{\circ} \mathrm{C}$, and comprised the fully equiaxed austenitic microstructure. The austenite grains of $20 \mathrm{Mn}$ and $27 \mathrm{Mn}$ steels have a slight growth, and generate a grain size of $21 \pm 4$ and $25 \pm 2 \mu \mathrm{m}$, respectively. The annealing twin boundaries are excluded in the measurement of effective grain size using EBSD. The tensile properties of the two experimental steels after annealing and the SFE calculated by the thermodynamic models [9] at room temperature are listed in Table 2. The corresponding true stress-strain curves and work hardening response are presented in Fig. 1.

As can be seen, the $27 \mathrm{Mn}$ steel displays both the lower strength and elongation than the steel $20 \mathrm{Mn}$. In the early stage of tensile deformation, the former maintains better work hardening ability until the 

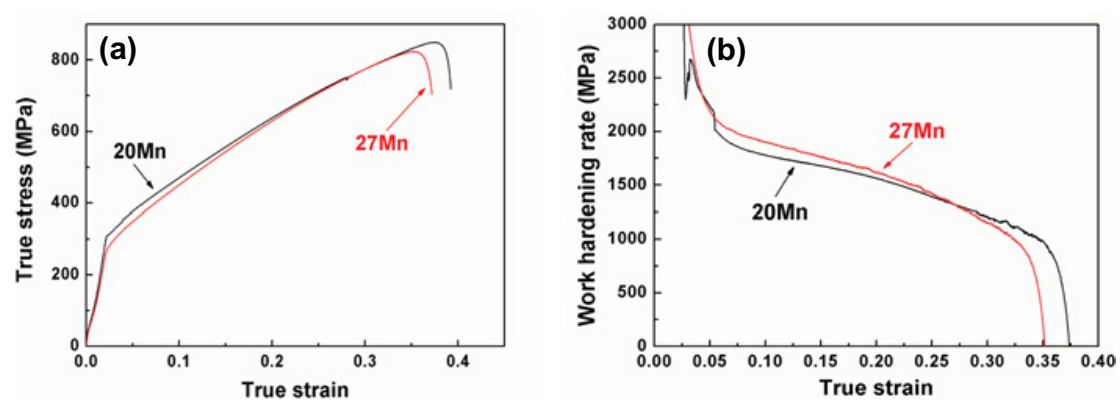

Figure 1. True stress-strain (a) and work hardening rate (b) curves under the uniaxial tension.

Table 3. Macro-hardness (HV) of the experimental steels after various tensile strains.

\begin{tabular}{|l|l|l|l|l|l|}
\hline True strain & 0 & 0.15 & 0.22 & 0.29 & 0.36 \\
\hline Hardness (20Mn) & 156.7 & 244.8 & 276.1 & 305.2 & 323.4 \\
\hline Hardness (27Mn) & 154.7 & 243.6 & 270 & 301.3 & 316.7 \\
\hline
\end{tabular}
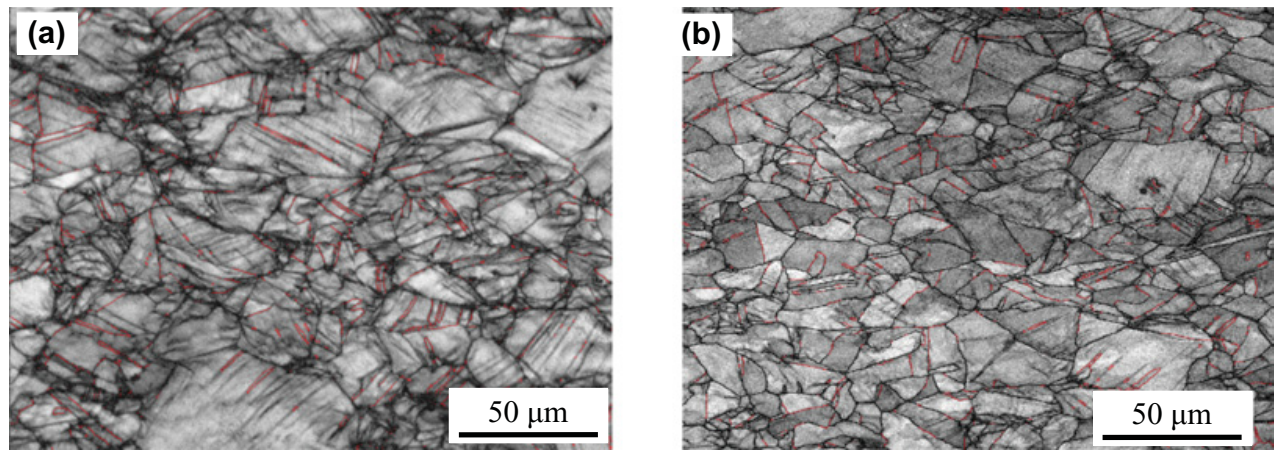

Figure 2. EBSD quality image of steels $20 \mathrm{Mn}$ (a) and $27 \mathrm{Mn}$ (b) after the tensile strain of 0.3 .

true strain reaches 0.27 . Both of the curves reveal a monotonously descending trend of work hardening rate up to fracture, instead of the typical five-stage response shown by most TWIP steels with low SFE [7]. However, at the onset of deformation, the decrease in strength can be explained by the Hall-Petch relationship and the elevated Mn content. On the one hand, the enhancement of $1 \mathrm{wt} \% \mathrm{Mn}$ content can roughly give rise to a reduction of $2 \mathrm{MPa}$ in yield strength for high $\mathrm{Mn}$ austenitic steels [10, 11], so that the decline of yield strength caused by the softening of Mn alloying should be nearly $14 \mathrm{MPa}$ in $27 \mathrm{Mn}$ steel. On the other hand, the minor distinction of grain size can also lead to an approximate drop of $14 \mathrm{MPa}$ in yield strength by estimating the constant $(K)$ of the Hall-Petch relation as $18 \mathrm{MPa} \cdot \mathrm{mm}^{1 / 2}$. Additionally, the macro-hardness of 20Mn steel always keeps a little larger than that of steel $27 \mathrm{Mn}$ throughout the whole work hardening process, as described in Table 3.

\subsection{Microstructure evolution during deformation}

Figure 2 shows the EBSD quality images of the 20Mn and 27Mn tensile samples at the true strain of 0.29 . There is no evidence of $\varepsilon / \alpha^{\prime}$-martensite transformation discovered by EBSD detection. For both experimental steels, the deformation twinning is quite difficult to be triggered until $\varepsilon=0.22$, due to the medium SFE and the low stress level. With further straining, the amount of deformation twins sharply increases, and their volume fractions as a function of deformation degree are plotted in Fig. 3. 


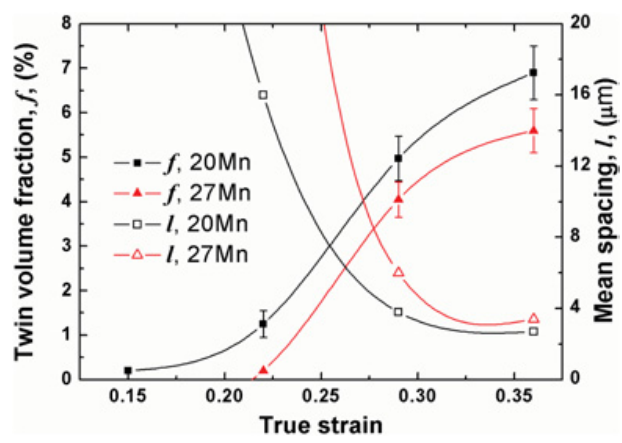

Figure 3. Twin volume fraction $f$ and mean spacing $l$ as a function of true strain.
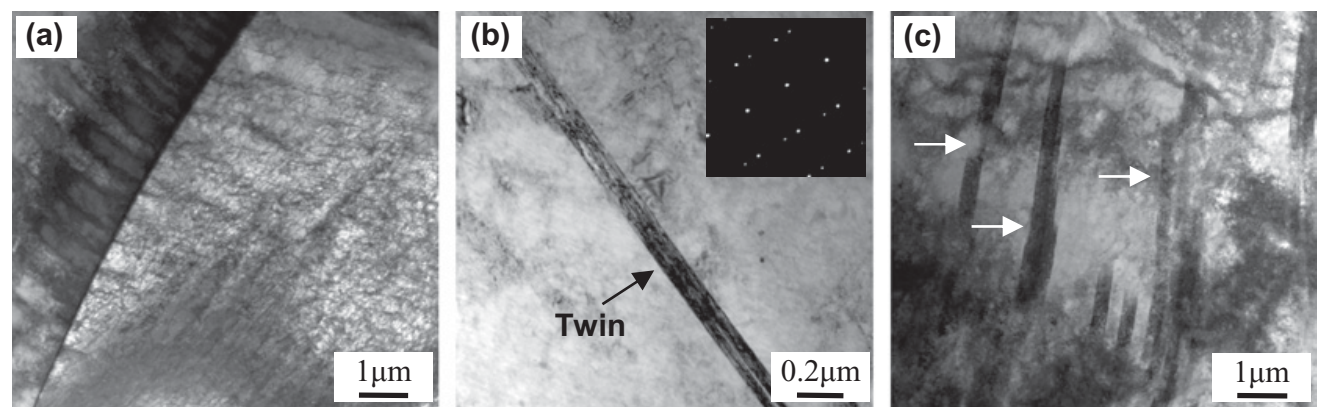

Figure 4. TEM images of (a) planar dislocation tangles in $20 \mathrm{Mn}$ steel at $\varepsilon=0.15$, (b) primary twin in $27 \mathrm{Mn}$ steel at $\varepsilon=0.22$, and (c) microbands in $27 \mathrm{Mn}$ steel at $\varepsilon=0.36$.

The mean spacing of twin lamella $(l)$ can also be estimated by the following equation [12]:

$$
l=2 t(1-f) / f
$$

where $f$ is the volume fraction of twin lamellae and their average thickness $t$ is taken as $100 \mathrm{~nm}$. It can be seen that the boom of deformation twinning is greatly inhibited by the medium SFE, compared with those high Mn austenitic steels having low SFE. This distinction explains why the work hardening curves keep dropping and fail to rise again for the experimental steels throughout the whole deformation process. Besides, the lowered tensile strength and uniform elongation of $27 \mathrm{Mn}$ steel should also be related to the reduced quantity of twin fraction because of the enhanced Mn content.

Although the occurrence of rare twin lamella is initiated in $20 \mathrm{Mn}$ steel at a true strain of 0.15 , the early stage of plastic deformation is essentially governed by the glide of planar dislocations. The interaction of Shockley partials in two conjugate $\{111\}$ planes produces a sessile dislocation forming the Lomer-Cottrell lock [13], which causes the pile-up and dislocation tangle, as shown in Fig. 4a. The multiple slip and located stress concentration are usually regarded as the necessary conditions for twin nucleation. Figure $4 \mathrm{~b}$ shows a resultant twin lamella of $27 \mathrm{Mn}$ steel with the thickness around $130 \mathrm{~nm}$ at the true strain of 0.22. Apart from deformation twins, a certain number of microbands (marked by white arrows in Fig. 4c) prefer to occur during the late stage of tensile deformation in steel $27 \mathrm{Mn}$ due to its elevated SFE, but their contribution to work hardening rate may not catch up with the twins.

Figure 5 shows the grain orientation spread (GOS) analysis of the interrupted tensile samples for steels 20Mn and 27Mn using EBSD. In essence, the GOS is the average difference in orientation between the average grain orientation and all measurements within a single grain [14]. Its value generally increases with the elevated strain. As the deformation degree exceeds the true strain of 0.3 , the average 

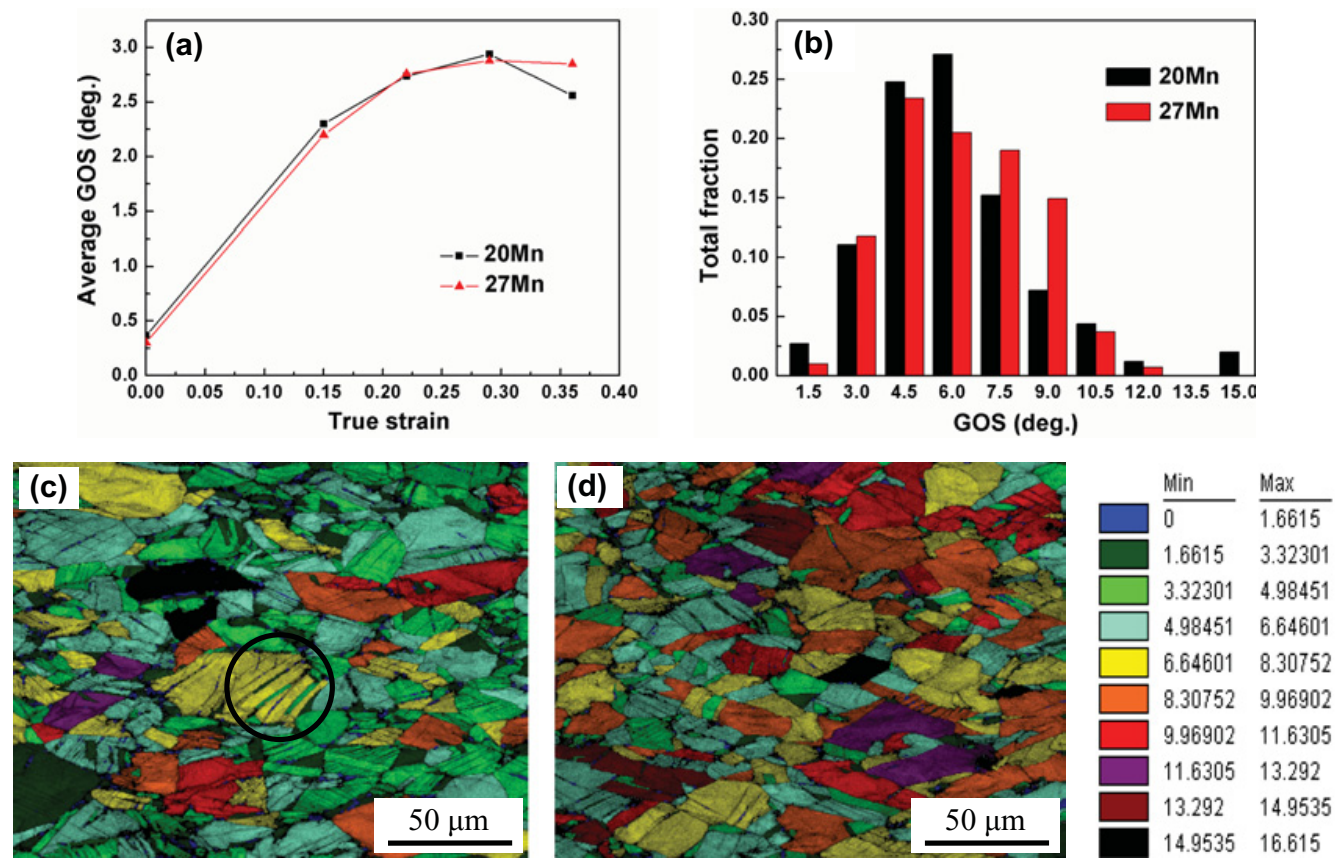

Figure 5. The variety of average GOS value with true strain (a), GOS distribution at the true strain of 0.36 (b), and colour maps of GOS distribution for steels $20 \mathrm{Mn}$ (c) and 27Mn (d) at the true strain of 0.36 .

GOS value for all grains generates a minor decline in steel 20Mn (Fig. 5a). The GOS distribution of both steels at the true strain of 0.36 also confirms this variety (Fig. 5b-d). The change should be connected with the continuous twinning process in the late stage of tensile deformation. Most grains favoring deformation twinning in the $20 \mathrm{Mn}$ steel usually own a lower GOS value in contrast to steel $27 \mathrm{Mn}$, and meanwhile, the newly formed twin lamellae further decrease the GOS level below that of their parent grains (See the black dashed circle in Fig. 5c). Moreover, the presence of twinning largely weakens the dependence of plastic deformation on slip and grain rotation, so that the locally high distortion can be released by triggering primary or secondary twins, instead of the development of those highly dense dislocation cells. Therefore, the $27 \mathrm{Mn}$ steel, which is more favourable for cross-slip due to the larger SFE, tends to rely on reducing dislocation cell size and further grain rotation to accomplish the final deformation, so that the GOS is increased as a whole.

\subsection{Charpy impact property}

The Charpy impact energy as a function of test temperature is plotted in Fig. 6a. The values of both steels diminish with the declining temperature. At $-196^{\circ} \mathrm{C}$, the $27 \mathrm{Mn}$ steel still exhibit the satisfying impact property, since there is no obvious ductile-brittle transformation temperature for austenitic structure. All the fractures are ductile, and the dimples in steel $27 \mathrm{Mn}$ are deeper and more evenly distributed for each test temperature.

Lee et al. [15] reported the Charpy impact property of Fe-(17-22)Mn-2Al-0.45C-0.007N steels, and discovered that the $\varepsilon / \alpha^{\prime}$-martensite transformation took place in the steels with $19 \mathrm{wt} . \%$ and $17 \mathrm{wt} \% \mathrm{Mn}$ at cryogenic temperature, but the martensite fraction of the former was rather limited. Since the SFE was lowered with the declining temperature and Mn content, the latter generated a sharp drop of total energy below $-100^{\circ} \mathrm{C}$ (Fig. 6b). Therefore, it is believed that the deterioration in the impact toughness of steel 

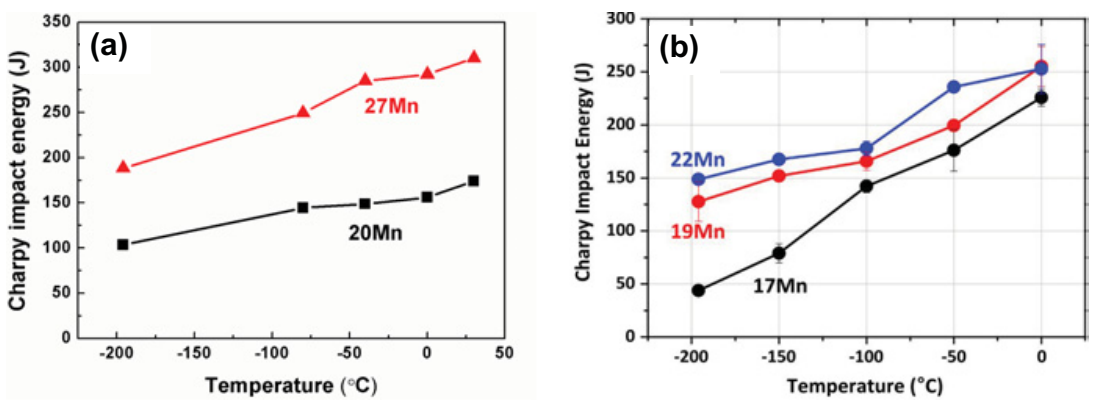

Figure 6. Charpy impact energy with decreasing temperature for the experimental steels (a) and Fe-(17/19/22)Mn2Al-0.45C steels (b) reported by Lee et al. [15].

$20 \mathrm{Mn}$ in present work should be ascribed to the larger amount of AlN inclusions and less addition of Mn solute [16]. The AlN impurity is mainly produced by the higher $\mathrm{N}$ content in steel making, and prefers to distribute along the rolling direction during the hot rolling process. When the impact load is applied, these inclusions can easily develop to the microvoids and be responsible for the ultimate fracture. On the other hand, the influence of martensite transformation can be ruled out in steel $20 \mathrm{Mn}$ because of its medium SFE and the absence of abrupt drop in the impact energy.

\section{Conclusions}

(1) As the declined Mn content, the 20Mn steel possesses both the higher strength and elongation than $27 \mathrm{Mn}$ steel, but the latter exhibits a better work hardening capacity at the onset of deformation. In addition, the former maintains a larger hardness than steel $27 \mathrm{Mn}$ after the same tensile strain.

(2) The medium SFE inhibits the occurrence of deformation twinning and promotes the formation of microbands in the late stage of tensile deformation. The maximum volume fraction of twin lamellae is less than $8 \mathrm{vol} \%$, and their mean spacing was also calculated. The lack for sufficient deformation twins finally results in the monotonously diminishing work hardening rate.

(3) The twinning process contributes to relieving the locally high distortion generated by the dislocation cross-slip inside the grains and accommodating further deformation. For this reason, the increase of GOS is slowed down to some extent.

(4) The $27 \mathrm{Mn}$ steel shows a superior impact property both at room temperature and $-196{ }^{\circ} \mathrm{C}$, where the Charpy impact energy is $310 \mathrm{~J}$ and $188 \mathrm{~J}$, respectively. The deterioration of impact property for steel $20 \mathrm{Mn}$ should be ascribed to its larger amount of AlN impurity and the reduced Mn addition.

\section{References}

[1] L.Q. Chen, Y. Zhao, X.M. Qin, Acta Metall. Sin. (Engl. Lett.) 26, 1 (2013)

[2] T. Sasaki, K. Watanabe, K. Nohara, Y. Ono, N. Kondo, S. Sato, Trans. ISIJ. 22, 1010 (1982)

[3] O. Bouaziz, S. Allain, C.P. Scott, P. Cugy, D. Barbier, Curr. Opin. Solid State Mater. Sci. 15, 141 (2011)

[4] I. Gutierrez-Urrutia, D. Raabe, Acta Mater. 59, 6449 (2011)

[5] J.E. Jin, Y.K. Lee, Acta Mater. 60, 1680 (2012)

[6] K.T. Park, K.G. Jin, S.H. Han, S.W. Hwang, K. Choi, C.S. Lee, Mater. Sci. Eng. A 527, 3651 (2010) 


\section{ICNFT 2015}

[7] J.D. Yoo, S.W. Hwang, K.T. Park, Metall. Mater. Trans. A 40, 1520 (2009)

[8] Z.Q. Wu, H. Ding, H.Y. Li, M.L. Huang, F.R. Cao, Mater. Sci. Eng. A 584, 150 (2013)

[9] S. Curtze, V.T. Kuokkala, Acta Mater. 58, 5129 (2010)

[10] O. Bouaziz, Scripta Mater. 66, 982 (2012)

[11] B.C. De Cooman, O. Kwon, K.G. Chin, Mater. Sci. Technol. 28, 513 (2012)

[12] G. Dini, R. Ueji, A. Najafizadeh, S.M. Monir-Vaghefi, Mater. Sci. Eng. A 527, 2759 (2010)

[13] I. Gutierrez-Urrutia, D. Raabe, Acta Mater. 60, 5791 (2012)

[14] N. Allain-Bonasso, F. Wagner, S. Berbenni, D.P. Field, Mater. Sci. Eng. A 548, 56 (2012)

[15] J. Lee, S.S. Sohn, S. Hong, B.C. Suh, S.K. Kim, B.J. Lee, N.J. Kim, S. Lee, Metall. Mater. Trans. A 45, 5419 (2014)

[16] S.E. Kang, A. Tuling, J.R. Banerjee, W.D. Gunawardana, B. Mintz, Mater. Sci. Technol. 27, 95 (2011) 